\title{
Em busca de um telejornalismo legítimo: critérios de qualidade nas críticas de Artur da Távola dos anos 1970
}

//////////// Fernanda Mauricio da Silva ${ }^{1}$

1. Doutora em Comunicação e Cultura Contemporâneas pela Universidade Federal da Bahia. Professora do Programa de Pós-graduação em Comunicação da Universidade Paulista. E-mail: fernandamauricio@ gmail.com 
Resumo Nos anos 1970, as críticas televisivas publicadas por Artur da Távola alçavam um novo lugar discursivo para o telejornalismo: em vez da cooptação com um entretenimento empobrecedor, a legitimidade impulsionada pelo jornalismo de rede e a tecnologia. Este artigo discute como Távola legitimava o telejornalismo por meio de um discurso de qualidade frente a outras mídias, evidenciando disputas de poder em torno da representação da realidade, do discurso emocional e da relação com o cotidiano.

Palavras-chave Telejornalismo, crítica televisiva, qualidade, legitimidade.

Abstract In the 1970s, the TV reviews published by Artur da Távola rose a new discursive place for TV journalism: instead of the approach with an impoverishing entertainment, a legitimate discourse through technology. This article discusses how Távola legitimated television journalism through a discourse of quality compared to other media, showing power struggles around the representation of reality, emotional speech and compared with everyday life.

Keywords Television journalism, critical reviews, quality, legitimacy. 
2. Freire Filho (2004) afirma que o entusiasmo dos primeiros anos da TV brasileira, marcado pelas amplas possibilidades de levar às massas uma cultura de alto nível, foi progressivamente dando lugar a uma visão negativa sobre o futuro do meio.
Introdução: a crítica do telejornalismo antes de 1970

A questão da qualidade na televisão brasileira está presente nos textos acadêmicos e jornalísticos desde as primeiras transmissões. Renato Ortiz (2006) afirma que o periódico Anhembi, em 1956, acrescentou em seu índice temático a rubrica "rádio e TV em 30 dias", que tinha como finalidade expor a opinião de intelectuais e literatos sobre o recém-inaugurado veículo de comunicação. A coluna apresentava posicionamentos sobre produtos, linguagens e o papel da TV na sociedade, assumindo uma perspectiva pessimista que revelava "o preconceito dos intelectuais em relação ao rádio e à televisão" (ORTIZ, 2006, p. 15). João Freire Filho (2004) também destaca a posição preconceituosa de literatos e intelectuais dos anos 1960 sobre a televisão. Segundo o autor, as primeiras transmissões televisivas, por usar o audiovisual, privilegiavam o sentido do entretenimento, sendo frequentemente associada ao popularesco e à baixa qualidade da programação ${ }^{2}$. $\mathrm{O}$ autor destaca que os "escritos canônicos a respeito da televisão incidem, em regra, numa falta grave: tendem a preferir a crítica impetuosa e a condenação moral à pesquisa sistemática e à reflexão teórica” (FREIRE FILHO, 2004, p. 87). Embora a expectativa sobre o papel social da TV perpasse constantemente pela maior presença de produtos jornalísticos, nos anos 1950 e 1960, a programação das emissoras dedicada a telenovelas, humorísticos, programas de auditório contrastava com as aspirações dos intelectuais.

Discutimos, em outra ocasião (SILVA, 2013), que os programas de entrevistas eram alvos constantes das disputas entre o jornalismo e o entretenimento televisivos em função do duplo caráter que 
a entrevista poderia assumir. Por ser uma prática relacionada ao jornalismo, as emissoras consideravam qualquer programa de entrevista como um produto jornalístico, o que não agradava os críticos do período. Uma reportagem da revista Veja, intitulada "A TV contra a notícia", destaca que os programas Hebe e Dercy de Verdade, apesar de apresentarem entrevistas, não tinham propósitos jornalísticos, funcionando como um pretexto das emissoras para cumprir a exigência de cinco por cento da programação destinada a informação, imposta pelo Ministério da Comunicação (A TV CONTRA..., 25 jun. 1969, p. 59).

Se tal tensionamento pode ser verificado até os anos 1960, na década seguinte o telejornalismo, impulsionado pela transmissão em rede e pela criação de novos formatos, buscou demarcar seu lugar de legitimidade frente a outras fontes informativas. Se anteriormente a crítica televisiva denunciava a baixa qualidade dos telejornais em função de sua justaposição ao entretenimento, nos anos 1970 o avanço do modelo hard news encontrou espaço para a criação de um discurso auto legitimador. Igor Sacramento (2008) afirma que o impulso promovido pelos grupos políticos e a racionalização da produção televisual contribuíram para que os conhecidos "programas de mundo cão" dessem lugar à informação de interesse nacional. Paralelamente a isso, emissoras se enquadravam às expectativas, importando não mais do rádio, mas do jornalismo impresso seus repórteres e apresentadores (MEMÓRIA GLOBO, 2004).

Uma das vozes mais entusiasmadas com esse momento do telejornalismo é a de Artur da Távola que, durante os anos 1970, atuou como crítico do jornal O Globo e da revista Amiga TV. Convencido de que o avanço tecnológico experimentado pelo telejornalismo era o principal responsável pelo acréscimo de sua qualidade, os textos de Távola, quando não exaltavam os predicados da atividade, apresentavam-se como um conjunto de procedimentos normativos, explicitando o que as equipes de redação precisariam fazer para corrigir seus erros e, por vezes, contornar a ausência de recursos técnicos. Por conta desse otimismo em relação ao telejornalismo, as críticas de Távola nos permitem reconhecer certos atributos que distinguiam e legitimavam o jornalismo de televisão no contexto midiático. Na contramão do pensamento predominante acerca do papel alienante da TV e da superficialidade do telejornal, Távola 
acreditava que era possível fazer jornalismo de qualidade na televisão e que as possibilidades do audiovisual corroboravam para isso.

Este artigo pretende refletir sobre os critérios destacados por Artur da Távola para a legitimação do jornalismo de televisão e a construção cultural de certos parâmetros de qualidade a partir dos textos publicados em O Globo e revista Amiga TV. Interessam menos, portanto, os programas avaliados do que as disputas evidentes na tentativa de promover o reconhecimento social do telejornalismo enquanto espaço para discussão de notícias, acionando recursos outros que se desdobram do audiovisual.

As práticas de avaliação dos gêneros: crítica, gosto e legitimação social

Enquanto gênero televisivo, o telejornalismo se constrói numa relação dinâmica e mutante entre marcas textuais (cenário, modelos de reportagem, etc.) e valores sociais (expectativas com relação à informação, formação da audiência, verdade na transmissão das notícias etc.). Sendo assim, os recursos de imagem e de som se combinam com um discurso cultural acerca do papel do jornalismo na sociedade, que o aproxima de valores historicamente formados, tais quais interesse público, vigilância, objetividade, atualidade (GOMES, 2011). Enquanto instituição social, o telejornal consolidouse culturalmente como o espaço para a transmissão das informações atuais sobre o país e o mundo, agindo, muitas vezes, como um intermediário entre os interesses dos receptores e os constrangimentos do campo político. A análise do telejornalismo, portanto, não compreende apenas os produtos televisivos, mas todo o conjunto de discursos que circula em torno dele e que constrói, em contrapartida, definições sociais sobre o que é (ou não) possível na prática jornalística. Tais definições, por sua vez, transformam-se com o tempo, deslocando sentidos anteriormente estabelecidos e apontando perspectivas futuras, provocando tensionamentos e estabelecendo convenções que se alinham à conjuntura de cada período. A crítica televisiva insere-se como um circuito possível para a transmissão de valores, opiniões, argumentos e normas sobre o telejornalismo. 
José Luiz Braga (2006) afirma que ao lado dos processos de produção e recepção na comunicação midiática, há um terceiro componente, ao qual denominou "sistema de interação social". Este atua como um sistema de resposta com o qual "a sociedade enfrenta sua mídia”, expressão que nomeia seu livro. Segundo Braga (2006), seja na crítica especializada, seja na produzida pela sociedade, os processos críticos realizam, pelo menos, três procedimentos:

\footnotetext{
a) exercem critérios, expressos ou implícitos, segundo os quais os produtos são observados; b) analisam características e especificidades dos produtos midiáticos postos em circulação; e c) lançam vetores interpretativos e/ou de ação em direção aos outros dois subsistemas (de produção e recepção) (BRAGA, 2006, p. 47).
}

Em sua pesquisa, Braga aborda a crítica como um dispositivo social que se relaciona com as outras esferas do processo comunicativo: a crítica pode contribuir com a produção para "aperfeiçoar" seu trabalho, pode fornecer informações acerca do produto midiático e pode contribuir com a formação da competência crítica dos receptores quanto ao que assistem, leem, ouvem.

Tendo em vista o modo como os processos críticos contribuem para a formação da sociedade, as análises de Braga são muito precisas em detectar o que é possível aprender com a crítica midiática, com vistas à formação da produção e da recepção. Gostaríamos, neste artigo, de destacar outro aspecto levantado pelo autor, não tanto sobre a atuação da crítica na sociedade, mas sobre o "enfrentamento tensional que, direta ou indiretamente, possa resultar em crítica interpretativa, ou em controle de desvios e equívocos midiáticos, em aperfeiçoamentos qualitativos, na defesa de valores sociais [...]" (BRAGA, 2006, p. 46). Ao definir os "processos críticos", Braga acentua um aspecto tensionador que busque a qualidade e a defesa de valores sociais. Ressaltamos o enfrentamento tensionador, pois acreditamos que, na relação com o gênero televisivo, a crítica pode promover certas disputas que visam marcar posições e lugares de fala acerca da definição dos 
gêneros. É de Jason Mittell (2004) a ideia de que são as práticas discursivas de avaliação - recorrentes nos textos críticos - que contribuem com a formação do gênero televisivo.

Mittell considera pertinente analisar os gêneros televisivos a partir de um sistema de pensamento predominante que, a todo modo momento, encontra-se tensionado pelos diversos agentes sociais. Assim, a crítica midiática publiciza disputas de poder pelo que pode ser feito ou não na televisão, o que pode ser considerado como uma prática de qualidade ou um desvio. Além disso, a crítica pode criar comunidades de sentido, posicionando a audiência quanto às suas preferências e seu gosto. Segundo Mittell, o gosto é "uma prática de constante mobilidade que reinscreve e constitui as divisões onde parecem estar localizados e naturalizados" (2004, p. 101).

As comunidades interpretativas criam regras e convenções por meio das quais as obras devem ser avaliadas a fim de legitimar seus próprios prazeres e afetos. Em nosso caso, os textos críticos de Artur da Távola estabelecem com seu leitorado uma relação especialista/ leigo através da qual é possível apontar os melhores programas, os jornalistas mais destacados e as práticas mais convincentes para a construção do bom jornalismo televisivo.

Os critérios de qualidade e legitimidade nas críticas de Artur da Távola

Num contexto em que ainda não havia a figura do ombudsman, nem o media criticism, o trabalho crítico sobre o telejornalismo pretendia assemelhar-se às demais críticas culturais. Entretanto, o quadro valorativo para avaliação dos produtos era um pouco mais difuso no caso do telejornalismo: num momento em que a própria linguagem televisiva está em formação, o que pode ser considerado uma boa reportagem, um bom telejornal, uma boa entrevista, bom jornalismo? Nos textos de Távola publicados na década de 1970, há uma intenção de compartilhar gostos e preferências pessoais, sem recorrer a parâmetros evidentes e consolidados para a atuação crítica. Seus principais alvos, sem dúvidas, eram os programas da TV Globo, especialmente Jornal Nacional, Globo Repórter e Fantástico, assumidos por Távola como um referencial de qualidade que as 
3. Não é nosso objetivo discutir os aspetos ideológicos que conduzem a crítica de Artur da Távola, tampouco posicionarmo-nos contrária ou favoravelmente a seus argumentos. demais emissoras deveriam aspirar. Os três programas apareciam na crítica como felizes inovações da linguagem televisiva e como agentes de dinamização da grade de programação que já mostrava, após vinte anos, certo desgaste. É notável na crítica de Távola a oposição novo x velho, moderno x tradicional, sendo que a Globo encontrava-se frequentemente no primeiro termo dessas equações ${ }^{3}$ e por isso, suas críticas configuravam-se como um espaço de consagração da emissora do Jardim Botânico. Do ponto de vista da construção do telejornalismo enquanto gênero televisivo, os textos contribuíam para consolidar um modelo dominante de jornalismo na televisão: aquele que se traduz pelo alto rigor técnico, pela plasticidade da imagem e por um conteúdo diversificado. De certa forma, o Padrão Globo de Qualidade em formação naquele período perpassa a crítica de Távola.

Segundo Renato Ortiz (2006), os anos 1970 caracterizam-se pela intensidade da construção da indústria cultural no Brasil e a televisão foi um dos veículos privilegiados para isso. A Ideologia de Segurança Nacional que permeava as ações do estado, ainda segundo o autor, perpetuava-se na forma de gerir e conceber a programação televisiva. Assim, um sentido de modernidade fazia-se evidente entre os empresários de televisão que, ao lado dos críticos, formavam um discurso em torno do novo, do moderno. As críticas de Artur da Távola alinham-se bastante com esse cenário. O "progresso da televisão" (TÁVOLA, 08 ago. 1974) era o que o motivava a escrever e, de certa forma, o seu objetivo final.

O interlocutor de suas críticas era o telespectador comum, aquele que, como ele, assistiu a um programa e formulou uma opinião a respeito. Por isso, ao dirigir-se ao seu leitorado, Távola assumia uma relação de proximidade, interpelando-o como "camaradinha leitor". Um vínculo de cumplicidade entre crítico e leitor se estabelecia, o que o levava a efetuar esclarecimentos e indicar assuntos que seriam tratados no dia seguinte.

Ao mesmo tempo, as críticas do autor traziam conhecimentos que o telespectador leigo não possuía. Távola não fundamentava seus argumentos em uma experiência prévia como profissional de televisão, tampouco num conhecimento de "bastidores". Como jornalista, também pouco tratava sobre as rotinas de produção para criticar os produtos. A força de seus textos parecia vir da própria 
4. Todos os textos foram extraídos do site TV Pesquisa, administrado pela Pontifícia Universidade Católica do Rio de Janeiro (http:// www.tv-pesquisa.com.puc-rio.br/).

As críticas serão referenciadas ao longo do texto pelo título e data de publicação. Nas referências bibliográficas situamos também o endereço eletrônico dos textos, bem como a data de acesso. relação de cumplicidade que comentamos acima, mas também de alguns conceitos acadêmicos que validavam seu argumento. "Aldeia global" e "indústria cultural" são alguns termos que permeiam suas críticas e que lhe conferem autoridade, consolidando um tom professoral.

Nossa análise restringe-se ao corpus de 28 textos de autoria de Artur da Távola publicados no jornal O Globo e na revista Amiga TV, entre 1972 e 19794, além de matérias e reportagens adjacentes sobre o telejornalismo do período que contribuíram para dar uma dimensão do lugar de fala do autor e as disputas que ele engendrava. A partir dos textos selecionados, localizamos pelo menos três posições de legitimidade e qualidade do telejornalismo nos anos 1970 que apresentamos a seguir.

As disputas midiáticas pela apreensão e construção da realidade

Bruno Leal e Phellipy Jácome, ao ampliarem o conceito de comunidade interpretativa jornalística proposto por Barbie Zelizer, argumentam que "como 'construtor de realidades' ofertadas periodicamente, o jornalismo sofre a concorrência de outras instituições sociais que têm papel semelhante" (LEAL; JÁCOME, 2013 , p. 48). Sendo assim, os autores assumem o termo comunidade não como um grupo separado de indivíduos - como uma tribo mas como uma metáfora para indicar "um espaço de circulação de valores e parâmetros avaliativos” (LEAL; JÁCOME, 2013, p. 51). Deste modo, se o jornalismo está em contato permanente com outras instituições, outros agentes devem fazer parte dessa "comunidade", de modo a legitimá-lo e possibilitar o reconhecimento de seu papel social. Entre esses agentes, Leal e Jácome destacam as fontes, os receptores e as mídias noticiosas como importantes locais de configuração do telejornalismo.

Interessa-nos em especial as colocações dos autores acerca da mídia noticiosa e seu lugar de conformação do jornalismo. Para eles, o processo de apreensão e construção da realidade não ocorre de maneira uniforme entre as diversas mídias noticiosas, mas estas disputam entre si por um lugar de prestígio e reconhecimento no (melhor) tratamento das informações. Sendo assim, um leitor não 
consome apenas uma notícia, mas uma notícia da Folha de S. Paulo, ou do New York Times. Segundo Leal e Jácome, o receptor, ao optar por um ou outro jornal, pela TV ou pela revista, para informar-se, "tem segurança sobre um conjunto de valores e referências que caracterizam o jornal ou a revista, a partir dos quais inclusive pode tomar esses ‘veículos’ como seus” (LEAL; JÁCOME, 2013, p. 56).

Em sua coluna na revista Amiga TV, Távola afirma que o jornalismo é a "vocação natural da TV" porque engloba as demais mídias, superando-as, portanto. Segundo o autor, a narrativa jornalística na televisão pode usar filmes cinematográficos, recorrer à oralidade típica do rádio e valer-se de gráficos e fotografias, como o jornal impresso (AMIGA TV, 1971, p.23). Além desse "poder aglutinador", a televisão é a única que, ao dispor simultaneamente de som e imagem, pode efetivamente traduzir a realidade. Sendo assim, o crítico busca estabelecer um traço distintivo do jornalismo de televisão em relação aos demais recorrendo a uma disputa de poder entre as mídias noticiosas.

Ainda de acordo com seu argumento, a televisão é o único espaço em que a realidade pode ser transmitida como um espelho e, por isso, em seu entender, ela supera as demais mídias. É necessário considerar o peso do determinismo tecnológico em suas críticas chegando inclusive a citar Marshal McLuham (nas edições de $\mathrm{O}$ Globo em 22 dez. 1972 e 11 jan 1973) - como se a qualidade televisiva fosse possível em função do avanço tecnológico, que permitiu maior mobilidade das equipes de TV, melhor captura de som e imagem etc. Nas críticas de Artur da Távola, o telejornalismo se legitima principalmente pelo alcance tecnológico dos equipamentos e é dessa forma também que a TV se diferencia dos demais veículos.

As críticas de Távola, embora posicionassem um lugar privilegiado da televisão em relação às outras mídias, não tinham qualquer intenção de superação, acusação ou destituição de outros veículos. Pelo contrário, Távola parecia defender que cada mídia exercesse plenamente seu papel, a fim de assegurar seu lugar no contexto midiático. Os textos de Távola enalteciam as possibilidades da TV em ampliar a cobertura noticiosa, dispondo de recursos tecnológicos que o rádio não possuía. No entanto, aponta para a necessidade de uma renovação na forma de efetuar locuções de modo a acompanhar o novo contexto. Assim, para ele, as inflexões dramáticas radiofônicas 
deveriam dar lugar ao estilo dialógico televisivo, tendo a conversação como parâmetro (TIRIRI-TIRIRI..., 23 nov. 1972). Deste modo, Távola inverte a ordem e afirma que o estilo radiofônico é que está sofrendo a influencia do televisivo e não o contrário, como no início da televisão. O modelo radiofônico tradicional aparece como "arcaico" quando afirma que "Everton Correia [locutor da Rádio Nacional] ainda pertence ao tempo em que para pronunciar a palavra milhões era preciso dizer 'milhoooões"' (LOCUTORES..., 20 nov. 1972). Esse modo de narrar, segundo Távola, representa um modelo excessivamente dramático, decorrente da ausência de imagens para esclarecer a informação. Uma crítica semelhante encontra-se em sua avaliação sobre a performance dos apresentadores do Jornal Nacional em São Paulo (DETALHES A CORRIGIR..., 18 dez. 1974), ou quando ressalta os esforços da TV Rio para realizar um telejornalismo de qualidade (UM LUGAR AO SOL, 08 ago. 1974).

As disputas midiáticas se tornam evidentes, também, no próprio desempenho de sua atividade crítica. Távola identifica dois horizontes específicos do crítico de televisão. O primeiro evidencia uma relação com o campo da produção: ao contrário dos críticos de teatro, cinema e literatura, que têm como objeto de avaliação uma "obra acabada", o crítico de televisão, através de seus comentários, pode interferir no processo de produção tendo em vista seu aperfeiçoamento. Por conta dessa compreensão os textos de Artur da Távola apresentam-se como prescrições em busca da "evolução da televisão". Ainda que reconheça que os processos críticos são mais estabelecidos em outros produtos culturais, Artur da Távola sugere que a crítica de televisão traz uma mudança significativa: poder "influir no processo de criação", o que, segundo ele, "é um ponto inteiramente diferente, novo e revolucionário na historia desse que gênero que se chama 'crítica'." (EXISTE MESMO CRÍTICA DE TV?, 29 out. 1976). Para ele, portanto, a obra televisiva é mais aberta que as demais, permitindo que os comentários que circulam nos paratextos interfiram nos produtos.

O segundo horizonte evidencia uma relação entre o trabalho crítico e a recepção: diferentemente das outras formas culturais, o objeto de avaliação do crítico de televisão é algo que a audiência já viu, o que, segundo Távola, gera um sentimento de partilha. A simultaneidade da recepção entre crítico e audiência provoca a criação de vínculos de quem "viveu em comum a emoção, a raiva, 
o apoio, o aplauso, a lágrima ou a indiferença" (TODO MUNDO GOSTA..., 30 OUT 1976). Assim, à função de orientação da audiência quanto ao processo de interpretar os produtos culturais, o crítico de TV acrescenta uma possibilidade de socialização que se estende por todo o ambiente televisivo, como abordaremos no item a seguir.

\section{A construção da realidade e o papel socializador da imagem}

Como consequência do pensamento determinista e tecnicista de Távola, a combinatória som/imagem deveria ter como finalidade a melhor representação da realidade. Enquanto jornalista, o autor pouco discutia as questões relacionadas ao trabalho de apuração e construção da pauta das reportagens. Também deixava transparecer que a TV poderia ser um espelho da realidade se essa combinatória obedecesse a parâmetros específicos. Sendo assim, para Távola, não era qualquer imagem televisiva que se apresentava como um reflexo do real, mas somente aquela imagem que narra os "fatos com a expressão viva de sua própria realidade" (AINDA A IMAGEM..., 22 dez. 1972).

A presença da imagem cotidianamente como forma de traduzir a realidade para o telespectador possuía, segundo o crítico, uma função que se justapunha à de transmitir informações. Távola acreditava que a imagem televisiva permitia o testemunho simultâneo de um acontecimento, gerando um laço entre os telespectadores. A imagem televisiva não precisaria ser "objetiva”, mas abria-se para a possibilidade de emocionar a audiência, o que enobrecia ao relato jornalístico. Assim, a imagem possuía, também, um papel socializador, unindo telespectadores dispersos através da emoção.

Artur da Távola introduz, por meio de suas críticas, um tema rechaçado tanto pela crítica jornalística, quanto pela crítica acadêmica ao telejornalismo. O discurso do jornalismo informativo prega que as notícias deveriam ser revestidas de uma capa de objetividade - entendida conforme o pensamento iluminista: a nãoopinião e não-emoção. Como o jornalismo brasileiro se modernizou nos anos 1950, buscando uma paridade com o modelo informativo norte-americano, a ideia de que o jornalismo se volta exclusivamente para os fatos e para o intelecto se sobrepunha a qualquer outro 
5. Entre eles destacam-se Gomes (2008) e Ornebring e Jönsson (2004). modelo de jornalismo que pretendesse se legitimar. Ainda hoje tal temática permeia as discussões acerca do jornalismo e, na televisão, ela ganha contornos mais expressivos. Recentemente é que autores têm feito um esforço de incluir a emoção e o entretenimento como um traço legítimo da narrativa jornalística ${ }^{5}$.

O papel socializador da imagem televisiva apresentava-se de forma mais evidente quando os programas pautavam temas trágicos. Uma polêmica sobre a TV poder ou não exibir imagens dramáticas (da guerra do Vietnam, por exemplo) estendeu-se na crítica de Távola, quando questionava se estaria sendo apelativa, perdendo seu caráter informacional e levando para a mesa de jantar imagens indigestas (TELEJORNALISMO OU SENSACIONALISMO I, 11 jan. 1973). Compreendendo que o compromisso dos jornalistas é com os fatos, Távola ultrapassava a questão da informatividade em sua discussão e discutia seu papel agregador: "quando a dramaticidade do real suplanta a da ficção e todos dela participam, uma nova forma de solidariedade e amor tem de estar nascendo (está, eu sei), caso contrário tudo será desesperança" (AINDA A IMAGEM..., 22 dez. 1972).

\section{A TV e o tempo do cotidiano: criando ritualidades}

Ao propor um mapa noturno para a análise das mediações televisivas, Martín-Barbero (2006) acata a dimensão do cotidiano em suas análises. Segundo o autor, a TV fala para e a partir do tempo do cotidiano, buscando estratégias para relacionar-se aos aspectos de reconhecimento da audiência. A essa propriedade, MartínBarbero denominou ritualidades, uma mediação que se encontra entre os formatos industriais e as competências de consumo. Através da ritualidade, os produtos televisivos acessam a memória do telespectador, seus hábitos de audiência, os sentidos partilhados. Ao mesmo tempo, é por meio da ritualidade que os produtos indicam os "trajetos de leitura" e posicionam as questões de gosto.

Por meio das críticas de Távola é possível ter uma breve dimensão dos usos que os receptores fazem dos produtos televisivos, assim como uma vinculação com transformações históricas. Ao indicar possíveis melhorias na programação jornalística televisiva, Artur da 
Távola sugere que a TV não deve perder de vista a relação com o cotidiano do telespectador a fim de fazer sentido.

Um exemplo dessa abordagem encontra-se no texto "Você tem gostado do telejornal “Amanhã'” (AMIGA TV, 27 ago. 1975). Ao abordar as carências do programa da Globo, Távola sustenta seu argumento na premissa de que o telejornal não conseguiu cumprir com as expectativas historicamente traçadas pela televisão no horário noturno - os programas do final da noite eram destinados ao aprofundamento da informação e não a um panorama de notícias. Sendo assim, ele se apresenta à audiência como um "repeteco" do Jornal Nacional. O programa cometeu dois erros: o primeiro foi romper com as expectativas com relação ao horário, o segundo, consequência deste, foi romper com os hábitos de audiência historicamente estabelecidos. Deste modo, a relação com as matrizes culturais são, também, um critério de qualidade do telejornalismo.

A própria condução da temática deveria estar relacionada ao cotidiano do telespectador. Caso não respeitasse os hábitos de vida, Távola compreendia como uma ruptura do papel do jornalismo na televisão. Este foi o caso da reportagem do Globo Repórter, em 18 de setembro de 1979, sobre animais peçonhentos. Ainda que a qualidade técnica fosse impecável, o tratamento do tema não foi suficientemente bem apresentado. Aliás, no final da década, Távola dava mais relevo ao conteúdo dos programas jornalísticos, e não apenas à combinatória som/imagem, que parece ter marcado seus textos no início da década. Távola ressaltava que enquanto as imagens do Globo Repórter foram impressionantes, o conteúdo foi secundário: "ficou de fora uma série de temas relacionados com o interesse da população. Tais temas, quando mencionados, o foram de maneira muito rápida, impossíveis de serem fixados pelos telespectadores". (UM PROGRAMA DE COBRAS..., 23 set. 1979). Esta é uma das poucas vezes em que um valor do jornalismo - interesse público - aparece no quadro valorativo do telejornalismo formulado por Artur da Távola. No caso, a falha do programa foi não ter dado informações suficientes ao telespectador sobre o que fazer em caso de picada de aranha, mordida de cobra etc. Assim, o lapso entre produto jornalístico e apropriação para o cotidiano torna-se um fator distintivo de um telejornalismo de qualidade. 


\section{Notas finais}

Não foi objetivo desta análise efetuar a "crítica da crítica" de Artur da Távola. Nossa intenção foi, apenas, refletir sobre os aspectos ressaltados em seus textos críticos sobre o telejornalismo e seu processo de legitimação, tendo em vista as especificidades do contexto televisivo na configuração do telejornalismo. Os aspectos abordados por ele revelam, sobretudo, o pensamento predominante e seus tensionamentos num período histórico em que o jornalismo televisivo passava por uma transição. Sendo assim, as disputas entre as mídias, o aspecto socializador da imagem e a relação com o cotidiano são expectativas sociais acerca do processo de produção, transmissão e recepção de notícias, que deveriam obedecer às potencialidades do audiovisual.

Sobre as disputas midiáticas, percebemos que Artur da Távola atuava não apenas no sentido de apontar o erro das coberturas, mas especialmente salientar os acertos, indicando explicitamente os caminhos para a melhora da prática jornalística, como se pode ver no texto "Detalhes a corrigir no telejornalismo" (AMIGA TV, 18 dez. 1974): a locução dos apresentadores do Jornal Nacional de São Paulo e a redefinição da pauta do Plantão de Notícias e do Jornal Internacional. Entusiasmado com a mídia televisiva, Távola acreditava que ela daria as novas "regras do jogo" para os demais meios, reconfigurando a cultura midiática.

Apesar disso, vale considerar que, até aquele período, apesar de o autor buscar observar o jornalismo a partir dos limites e possibilidades do contexto televisivo, os critérios de avaliação ainda estavam vinculados a outras mídias. A designação dos apresentadores de telejornal de "locutores" - fazendo remissão ao rádio -, assim como os critérios utilizados para a observação de sua performance - dicção, inflexões, tom da voz - , indicam uma transição rumo à consolidação da linguagem televisiva, típica desse momento histórico. Essa aparente contradição sinaliza para as transformações que se colocariam nos anos seguintes.

Sobre o aspecto socializador da imagem, Távola argumentava contrariamente aos jornalistas tradicionais e intelectuais que acreditavam que a emoção e a proximidade com o entretenimento empobreciam o jornalismo. Para Távola, era possível à televisão emocionar o telespectador sem perder a qualidade. 
O último aspecto, a relação com as ritualidades, ressalta o lugar dos programas televisivos na própria história do meio. Embora pouco fizesse vinculações com o aspecto histórico, as críticas de Távola davam vislumbres dessa relação, quando compara a qualidade de produtos da Globo e da TV Tupi (LUGAR AO SOL, 08 ago. 1974), ou quando recorre ao conhecimento do telespectador sobre as matrizes culturais televisivas.

Embora seja possível pensar que Artur da Távola era excessivamente entusiasmado com a produção televisiva dos anos 1970, suas críticas não buscavam prioritariamente o erro, mas os acertos, os elementos que impulsionavam a produção. Certamente, uma relação com outros críticos poderia nos dar mais elementos para a reflexão. Por ora, cabe a este artigo sinalizar para alguns elementos que podem ser proveitosos para a compreensão do telejornalismo na história da televisão. 


\section{Referências}

BRAGA, J. L. A sociedade enfrenta a sua mídia: dispositivos sociais de crítica midiática. São Paulo: Paulus, 2006.

FREIRE FILHO, J. 'Notas históricas sobre o conceito de qualidade na crítica televisual brasileira'. Galáxia, 2004, número 7, pp. 85-110.

GOMES, I. Gênero televisivo como categoria cultural: um lugar no centro do mapa das mediações de Jesus MartínBarbero. Famecos, Porto Alegre, vol. 18, n. 1, pp. 111-130, jan/ abril, 2011. Disponível em: <http://revistaseletronicas.pucrs. br/ojs/index.php/revistafamecos/article/viewFile/8801/6165>. Acesso em: set. 2011.

GOMES, I. O embaralhamento de fronteiras entre informação e entretenimento e a consideração do jornalismo como processo cultural e histórico, in DUARTE, E. Em torno das Mídias: práticas e ambiências. Porto Alegre: Sulina, 2008. p. 95-112.

GOMES, I. Questões de método na análise do telejornalismo: premissas, conceitos, operadores de análise. E-Compós, v. 8, p. $1-31,2007$.

LEAL, B; JÁCOME, P. Outros agentes na comunidade interpretativa do jornalismo. Rumores, n. 14, vo. 17, jul-dez 2013, pp. 45-61.

MARTÍN-BARBERO, J. Dosmeios às mediações: comunicação, cultura e hegemonia, Rio de Janeiro: Editora UFRJ, 2009.

MEMÓRIA GLOBO. Jornal Nacional: a notícia faz história. Rio de Janeiro: Zahar, 2004.

MITTELL, J. Genre and Television: from cop shows to cartoons in American culture. London: Routledge, 2004. pp. 94-120. 
ÖRNEBRING, H; JÖNSSON, A. M. Tabloid journalism and the Public Sphere, 15:e Nordiska konferensen för medie- och kommunikationsforskning, Reykjavik, 11-13 augusti 2004, Arbetsgrupp: Mediehistoria (capturado em <http://www. nordicom.gu.se/mr/iceland/papers/five/AMJonsson.doc $>$. Acesso em 26 jan. 2008.

ORTIZ, R. A Moderna Tradição Brasileira. São Paulo: Brasiliense, 2006.

SACRAMENTO, I. Por um jornalismo televisivo de alto nível: as definições de qualidade na crítica especializada em duas décadas (1970/1980). In: VI ENCONTRO NACIONAL DE HISTÓRIA DA MÍDIA: 200 anos de mídia no Brasil historiografia e tendências, Rio de Janeiro, 2008. Disponível em: <http://www.ufrgs.br/alcar/encontros-nacionais-1/6oencontro-2008-1/Por\%20um\%20jornalismo\%20televisivo\%20 de\%20alto\%20nivel.pdf>. Acesso em 19 abr. 2013.

SILVA, F. M. Convenções históricas do talk show brasileiro: de 1950 a 1990. Eco-Pós, v. 16, n. 2, p. 191-204, mai./ago. 2013, pp. 191-204.

\section{Textos de periódicos consultados (em ordem cronológica)}

A TV CONTRA a notícia. Revista Veja, 25 jun. 1969, p. 59.

LOCUTORES, os astros da notícia. In: Jornal O Globo, 21 nov. 1972. Disponível em <http://www.tv-pesquisa.com.pucrio.br/mostraregistro.asp?CodRegistro $=61405 \& \mathrm{PageNo}=\mathrm{l}>$. Acesso 19 abr. 2013.

BOMBARDEIOS, disfunções e outras amenidades. In: Jornal O Globo, 07 dez. 1972. Disponível em: $<$ http://www.tv-pesquisa.com.puc-rio.br/mostraregistro. asp?CodRegistro=381\&PageNo=l>. Acesso 19 abr. 2013. 
AINDA A IMAGEM, agora na tragédia. In: Jornal O Globo, 22 dez. 1972. Disponível em <http://www.tv-pesquisa.com.pucrio.br/mostraregistro.asp?CodRegistro $=50952 \& \mathrm{PageNo}=\mathrm{l}>$. Acesso em 19 abr. 2013.

TELEJORNALISMOousensacionalismoI.In:JornalOGlobo, 11 jan. 1973. Disponível em <http://www.tv-pesquisa.com.pucrio.br/mostraregistro.asp?CodRegistro=33445\&PageNo=l>. Acesso em 19 abr. 2013.

TELEJORNALISMOousensacionalismoII.In:JornalOGlobo, 12 jan. 1973. Disponível: <http://www.tv-pesquisa.com.pucrio.br/mostraregistro.asp?CodRegistro $=33445 \& \mathrm{PageNo}=3>$. Acesso em 07 mai. 2013.

O NEGRO EM NOSSA CULTURA: joia. In: Jornal O Globo, 02 fev. 1973. Disponível: <http://www.tv-pesquisa.com. puc-rio.br/mostraregistro.asp?CodRegistro $=694 \& \mathrm{PageNo}=\mathrm{l}>$. Acesso em 19 abr. 2013.

TRÊS RESPINGOS da semana passada. In: Jornal O Globo, 27 fev. 1973. Disponível em: <http://www.tv-pesquisa.com. puc-rio.br/mostraregistro.asp?CodRegistro=779\&PageNo=l>. Acesso em 19 abr. 2013.

JORNAL O GLOBO, 26 jun. 1974. Disponível em: $<$ http://www.tv-pesquisa.com.puc-rio.br/mostraregistro. asp?CodRegistro=927\&PageNo=l>. Acesso em 19 abr. 2013.

O LUGAR AO SOL. In: Jornal O Globo, 08 ago. 1974. Disponível em: <http://www.tv-pesquisa.com.puc-rio.br/ mostraregistro.asp?CodRegistro=947\&PageNo=l $>$. Acesso em 19 abr. 2013.

JORNAL O GLOBO. 10 out. 1974. Disponível em: $<$ http://www.tv-pesquisa.com.puc-rio.br/mostraregistro. asp?CodRegistro=950\&PageNo=l>. Acesso em 19 abr. 2013.

JORNAL O GLOBO. 10 ago. 1974. Disponível: <http:// www.tv-pesquisa.com.puc-rio.br/mostraregistro. asp?CodRegistro=949\&PageNo=1>. Acesso em 19 abr. 2013. 
HERON DOMINGUES. In: Jornal o Globo, 21 ago. 1974. Disponível em: <http://www.tv-pesquisa.com.puc-rio.br/ mostraregistro.asp?CodRegistro $=962 \& \mathrm{PageNo}=\mathrm{l}>$. Acesso em 19 abr. 2013.

TELEJORNALISMO: ficção e realidade de mãos dadas. In: Revista Amiga TV, 04 set. 1974. Disponível em: $<$ http://www.tv-pesquisa.com.puc-rio.br/mostraregistro. asp?CodRegistro $=55870 \&$ PageNo=4>. Acesso em 14 mar. 2012.

GLOBO REPÓRTER em horário nobre é vitória do telejornalismo. In: Revista Amiga TV, 09 out. 1974. Disponível em: <http://www.tv-pesquisa.com.puc-rio.br/mostraregistro. asp?CodRegistro=1014\&PageNo=l>. Acesso em 19 abr. 2013.

A ALEGRIA DO ESPORTE. In: Jornal O Globo, 12 nov. 1974. Disponível em: <http://www.tv-pesquisa.com.pucrio.br/mostraregistro.asp?CodRegistro=1034\&PageNo=l>. Acesso em 19 abr. 2013.

DETALHES a corrigir no telejornalismo. In: Revista Amiga TV, 18 dez. 1974. Disponível em: <http:// www.tv-pesquisa.com.puc-rio.br/mostraregistro. asp?CodRegistro=50949\&PageNo=5 $>$. Acesso em 14 mar. 2012.

COMO ANDOU o telejornalismo em 1974. In: Revista Amiga TV,08jan. 1975.Disponível:<http://www.tv-pesquisa.com.pucrio.br/mostraregistro.asp?CodRegistro=1119\&PageNo=5>. Acesso em 14 mar. 2012.

ARTIGUINHO COMPLICADO. In: Jornal O Globo, 17 mar. 1975. Disponível em: <http://www.tv-pesquisa.com.pucrio.br/mostraregistro.asp?CodRegistro=55871\&PageNo=l $>$. Acesso em 19 abr. 2013.

VOCÊ TEM GOSTADO do telejornal 'Amanhã?. In: Revista Amiga TV, 27 ago. 1975. Disponível em: $<$ http://www.tv-pesquisa.com.puc-rio.br/mostraregistro. asp?CodRegistro=1334\&PageNo=1>. Acesso em 19 abr. 2013. 
EXISTE MESMO a crítica de TV?. In: Jornal O Globo, 29 out. 1976. Disponível em: <http://www.tv-pesquisa.com.pucrio.br/mostraregistro.asp?CodRegistro $=41328 \& \mathrm{PageNo}=1>$. Acesso em 19. Abr. 2013.

TODO MUNDO GOSTA de com quem concorda. In: Jornal O Globo,30out. 1976.Disponívelem:<http://www.tv-pesquisa.com. puc-rio.br/mostraregistro.asp?CodRegistro $=1579 \& \mathrm{PageNo}=15>$. Acesso em 09 mai. 2013.

ATO LEIGO de contrição. In: Jornal O Globo, 31 out. 1976. Disponível em: <http://www.tv-pesquisa.com.puc-rio.br/ mostraregistro.asp?CodRegistro $=41329 \& \mathrm{PageNo}=1>$. Acesso em 19 abr. 2013.

COMO DEVE SER o telejornal de uma emissora educativa. In: Jornal O Globo, 23 jun. 1977. Disponível em: $\quad<$ http://www.tv-pesquisa.com.puc-rio.br/mostraregistro. asp?CodRegistro=1621\&PageNo=1>. Acesso em 19 abr. 2013.

OS TEMAS QUE O POVO pretende ver da tevê. In: Jornal O Globo, 08 out. 1978. Disponível em: <http://www.tv-pesquisa. com.puc-rio.br/>. Acesso 10 jan. 2012.

O PEDÁGIO DO ABSURDO. In: Jornal O Globo, 11 fev. 1979. Disponível em: <http://www.tv-pesquisa.com.puc-rio.br/ mostraregistro.asp?CodRegistro $=2441 \& \mathrm{PageNo}=1>$. Acesso em 19 abr. 2013.

VIDAS QUE CABEM na vida da gente. In: Jornal O Globo, 01 jul. 1979. Disponível em: <http://www.tv-pesquisa.com. puc-rio.br/mostraregistro.asp?CodRegistro $=2581 \& \mathrm{PageNo}=\mathrm{l}>$. Acesso em 19 abr. 2013.

UM PROGRAMA de cobras sem lagartos. In: Jornal O Globo, 23 set. 1979. Disponível em: <http://www.tv-pesquisa.com. puc-rio.br/mostraregistro.asp?CodRegistro=2681\&PageNo=l $>$. Acesso em 19 abr. 2013.

TELEJORNALISMO É O QUENTE da televisão. In: Revista Amiga TV, 1971, p. 23. 
A TELEVISÃO BRASILEIRA está sendo desvirtuada. In: Última Hora. 08 de agosto de 1978, p. 14.

Artigo recebido em março e aprovado em junho de 2014. 